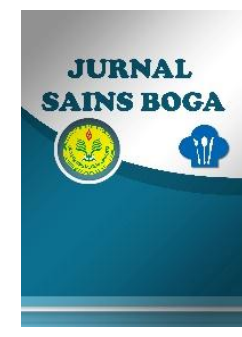

Vol. 4 No. 2, 2021

Page 34-39

DOI: https://doi.org/10.21009/JSB.004.2.01

E-ISSN: 2622-5557

Journal homepage: journal.unj.ac.id/unj/index.php/boga

\title{
Pengaruh Penggunaan Cairan (Susu UHT, Santan Segar, dan Santan Instan) pada Pembuatan Macaroni Schotel Terhadap Daya Terima Konsumen
}

\author{
Aulia Aufan Abdurrahman ${ }^{1, \text { a) }}$, Annis Kandriasari2, b) ${ }^{2}$ Rusilanti $^{3), c)}$ \\ ${ }^{1,2,3}$ Program Studi Pendidikan Tata Boga, Universitas Negeri Jakarta, Jalan Rawamangun Muka, \\ DKI Jakarta, 13220 \\ Email: ${ }^{\text {a) }}$ aufan030996@gmail.com, ${ }^{\text {b) }}$ annis@unj.ac.id , ${ }^{\mathrm{c})}$ rusilanti@gmail.com
}

\begin{abstract}
The objective of this study was to determine and analyze the effect of the usage of liquid (UHT milk, fresh coconut milk, and instant coconut milk) on Macaroni Schotel on consumer acceptance based on aspects of color, taste, aroma, and texture. This research was conducted at the Pastry and Bakery Laboratory of Food \& Nutrition Program, State University of Jakarta. When the study began in October 2019 until March 2020. The method used was an experimental method. The sample in this study was a Macaroni Schotel with the usage of $400 \mathrm{ml}$ liquid (UHT milk, fresh coconut milk, and instant coconut milk) tested on 30 untrained panelists who assessed all aspects. Based on the results of hypothesis analysis using the Friedman test on aspects of color, taste, and texture showed the effect of the usage of liquid (UHT milk, fresh coconut milk, and instant coconut milk) to the making of Macaroni Schotel does not have a signficant effect on consumer's acceptance so the formula for using the coconut milk must be tested again to gain better results.
\end{abstract}

Key words: macaroni schotel, UHT milk, coconut milk, fresh coconut milk, instant coconut milk

\begin{abstract}
Abstrak
Penelitian ini bertujuan untuk mengetahui dan menganalisis pengaruh penggunaan cairan (susu UHT, santan segar, dan santan instan) terhadap daya terima konsumen berdasarkan aspek warna, rasa, aroma, dan tekstur. Penelitian ini dilakukan di Laboratorium Pengolahan Pastry dan Bakery Program Studi Tata Boga, Fakultas Teknik, Universitas Negeri Jakarta. Waktu penelitian dimulai pada bulan Oktober 2019 hingga Maret 2021. Metode yang digunakan adalah metode eksperimen. Sampel pada penelitian ini adalah Macaroni Schotel menggunakan cairan susu UHT, santan segar, dan santan instan dengan ukuran 400ml yang kemudian diujikan kepada 30 panelis tidak terlatih yang menilai keseluruh aspek. Berdasarkan hasil uji hipotesis dengan menggunakan uji Friedman pada aspek warna, rasa, dan tekstur menunjukan bahwa penggunaan cairan (susu UHT, santan segar, dan santan instan) tidak memiliki pengaruh yang signifikan pada penerimaan konsumen sehingga formula penggunaan santan harus diuji kembali agar mendapatkan hasil yang lebih baik.
\end{abstract}

Kata kunci: macaroni schotel, susu UHT, santan, santan segar, santan instan

\section{PENDAHULUAN}

Pasta adalah makanan olahan yang banyak digunakan pada masakan Italia. Pasta dijadikan berbagai hidangan setelah dimasak dengan cara direbus atau digoreng. Hidangan dengan bahan dasar pasta telah menjadi favorit banyak orang dikarenakan oleh cara pembuatannya yang mudah dan dapat disajikan dalam berbagai variasi hidangan dan suasana (Brotodjojo, 2009). 
Pasta terbuat dari tepung terigu semolina yang merupakan hasil gilingan biji gandum durum dicampur telur sehingga sedikit berwarna kuning cerah, dan ketika diolah dengan benar menghasilkan tekstur sedikit kenyal. Pasta Amerika sering dibuat dari campuran tepung terigu farina dan semolina, sehingga mempunyai tekstur yang lebih lembut untuk dijadikan hidangan seperti kaserol.

Menurut Hamilawati (2005), pasta dikelompokkan menjadi 2 jenis yaitu pasta segar (fresh pasta) dan pasta kering (dried pasta). Pasta segar buatan rumah tangga dan restoran dibentuk dengan tangan beberapa saat sebelum pasta direbus. Pasta segar memerlukan waktu masak yang singkat, namun pasta segar tidak memiliki waktu simpan yang lama dikarenakan memiliki kadar air yang tinggi. Selanjutnya ada yang disebut dengan pasta kering yaitu jenis pasta yang dapat disimpan dengan waktu yang lama hingga 3 tahun dikarenakan pasta kering hanya memiliki $10 \%$ kandungan air di dalamnya. Pasta kering yang dibuat dari gandum durum ditemukan di Italia pada tahun 800-an. Penemunya adalah umat Muslim Sicily Italia yang menyebarkan dan menyempurnakan teknik pengeringan untuk pasta kering tersebut. (De Vita, 2009).

Pasta kering dibagi menjadi dua tipe yaitu long dan short pasta. Long pasta yang biasa ditemukan adalah spaghetti, long macaroni, dan fettucinne. Sedangkan untuk short pasta biasa ditemukan dengan nama gobbeti, spiral macaroni, chifferi rigate, cociolini, fusili dan penne (Mc Guire, 2012). Di Indonesia jenis pasta yang populer adalah spaghetti, lasagna dan macaroni.

Macaroni merupakan pasta yang berbentuk huruf $\mathrm{C}$ atau Elbow. Macaroni dapat diolah dengan saus atau menjadi isian dalam hidangan sup, selain itu macaroni juga bisa dihidangkan dengan bahan lainnya seperti daging ayam, sayur - sayuran, daging sapi, atau banyak lainnya menjadi suatu hidangan seperti Mac $n$ Cheese, Macaroni Pudding, Macaroni Salad, dll.

Dengan banyaknya variasi masakan dari macaroni, ada satu hidangan yang disebut dengan Macaroni Schotel. Macaroni Schotel biasanya ditambahkan dengan daging, keju, atau tuna dan bahkan terkadang diberikan tambahan kentang dan tahu agar menjadi suatu hidangan yang dapat diterima oleh lidah masyarakat Indonesia. Adapun beberapa penelitian yang sudah dilakukan diantaranya yaitu oleh Anita Suryani (2012) tentang pemakaian kentang terhadap masakan kontinental (Macaroni Schotel),hasil dari penelitian yang dilakukan oleh Anita Suryani terhadap Macaroni Schotel adalah diterima dengan baik.

Macaroni Schotel adalah suatu jenis kue asin basah yang dalam pembuatannya menggunakan macaroni, telur, dan cairan sebagai bahan utama dalam pembuatannya. Macaroni berfungsi sebagai sumber karbohidrat, telur berfungsi untuk mengikat seluruh adonan untuk pembuatan Macaroni Schotel sedangkan cairan yang digunakan akan menjadi bahan pelembut tekstur dari Macaroni Schotel.

Kali ini, peneliti akan melakukan uji coba pada cairan Macaroni Schotel dengan menggunakan 3 jenis cairan yang berbeda yaitu susu UHT, santan segar, dan santan instan. Peneliti ingin mempelajari bagaimana pengaruh tiga jenis cairan yang akan digunakan pada macaroni schotel terhadap daya terima konsumen pada aspek rasa, aroma, warna dan tekstur.

\section{METODE PENELITIAN}

Metode yang digunakan dalam penelitian ini adalah eksperimen yaitu percobaan yang dilakukan sesuai dengan rancangan yang dibuat. Eksperimen dalam pembuatan Macaroni Schotel dengan memberikan perlakuan subtitusi penggunaan cairan menggunakan santan. Selanjutnya dilakukan pengujian terhadap daya terima konsumen dengan menggunakan uji hedonik.

Uji organoleptik kemudian dilakukan kepada 30 orang panelis tidak terlatih yaitu tetangga dan keluarga dekat yang bersedia untuk memberikan tanggapan. Alasan peneliti memilih panelis tidak terlatih yaitu tetangga dan keluarga dekat sebagai panelis adalah dikarenakan situasi pandemi covid 19 yang sedang terjadi saat ini di Indonesia, Dimana sebelumnya dilakukan juga uji kualitas produk dengan 5 orang panelis dosen ahli Program Studi Tata Boga, Fakultas Teknik, Universitas Negeri Jakarta untuk memilih Macaroni Schotel dengan subtitusi cairan santan instan cair dan murni yang memenuhi standar. 


\section{HASIL DAN PEMBAHASAN}

Pada penelitian ini bertujuan untuk mengetahui dan mempelajari pengaruh penggunaan cairan pada pembuatan Macaroni Schotel dengan penggunaan cairan susu UHT, santan segar, dan santan instan. Penilaian dilakukan kepada 5 panelis ahli yang berasal dari dosen ahli dan kepada 30 panelis tidak terlatih yang berasal dari masyarakat tempat peneliti tinggal yang meliputi aspek warna, rasa, aroma, dan tekstur kemudian diolah menjadi data dan disimpulkan secara deskriptif dan diuji melalui uji hipotesis statistik.

TABEL 1. Hasil Uji Validasi Aspek Aroma

\begin{tabular}{|c|c|c|c|c|c|c|c|}
\hline \multirow{3}{*}{ Kategori } & \multirow{3}{*}{ Skor } & \multicolumn{6}{|c|}{ Schotel Penggunaan cairan } \\
\hline & & \multicolumn{2}{|c|}{ Susu UHT } & \multicolumn{2}{|c|}{ Santan Segar } & \multicolumn{2}{|c|}{ Santan Instan } \\
\hline & & $\mathbf{n}$ & $\%$ & $\mathbf{n}$ & $\%$ & $\mathbf{n}$ & $\%$ \\
\hline Sangat suka & 5 & 1 & 3,3 & 1 & 3,3 & 10 & 33,3 \\
\hline Suka & 4 & 28 & 93,3 & 28 & 93,3 & 18 & 60 \\
\hline Agak suka & 3 & 1 & 3,3 & 1 & 3,3 & 2 & 6,6 \\
\hline Tidak suka & 2 & 0 & 0 & 0 & 0 & 0 & 0 \\
\hline Sangat tidak suka & 1 & 0 & 0 & 0 & 0 & 0 & 0 \\
\hline Jumlah (n) & & 30 & 100 & 30 & 100 & 30 & 100 \\
\hline Mean & & \multicolumn{2}{|c|}{4} & \multicolumn{2}{|c|}{4} & \multicolumn{2}{|c|}{4,26} \\
\hline
\end{tabular}

Aspek aroma penggunaan cairan susu UHT memperoleh nilai rata-rata 4 (suka), untuk cairan santan segar memperoleh nilai rata-rata 4 (suka), sedangkan Macaroni Schotel dengan penggunaan cairan santan instan memperoleh nilai rata-rata 4,26 (suka). Setelah melalui uji friedman didapatkan hasil bahwa tidak terdapat pengaruh dalam aspek aroma dengan nilai $\mathrm{x}^{2}$ hitung $-0,14$, nilai signifikan $\alpha=0,05$ dan $\mathrm{x}^{2}$ tabel 5,99. Jika dlihat dari data, perbedaan penilaian aroma macaroni schotel dengan penggunaan cairan susu UHT, santan segar dan santan instan tidak signifikan.

TABEL 2. Hasil Uji Validasi Aspek Warna

\begin{tabular}{|c|c|c|c|c|c|c|c|}
\hline \multirow{3}{*}{ Kategori } & \multirow{3}{*}{ Skor } & \multicolumn{6}{|c|}{ Macaroni Schotel Dengan Penggunaan Cairan } \\
\hline & & \multicolumn{2}{|c|}{ Susu UHT } & \multicolumn{2}{|c|}{ Santan Segar } & \multicolumn{2}{|c|}{ Santan Instan } \\
\hline & & $\mathbf{n}$ & $\%$ & $\mathbf{n}$ & $\%$ & $\mathbf{n}$ & $\%$ \\
\hline Sangat suka & 5 & 2 & 6,6 & 0 & 0 & 13 & 43,3 \\
\hline Suka & 4 & 27 & 90 & 22 & 73,3 & 14 & 46,6 \\
\hline Agak suka & 3 & 1 & 3,3 & 8 & 26,6 & 3 & 10 \\
\hline Tidak suka & 2 & 0 & 0 & 0 & 0 & 0 & 0 \\
\hline Sangat tidak suka & 1 & 0 & 0 & 0 & 0 & 0 & 0 \\
\hline Jumlah (n) & & 30 & 100 & 30 & 100 & 30 & 100 \\
\hline Mean & & 4,03 & & & & & 4,33 \\
\hline
\end{tabular}

Hasil penelitian untuk aspek warna Macaroni Schotel penggunaan cairan susu UHT memperoleh nilai rata-rata 4,03 (suka), persentase santan segar memperoleh nilai rata-rata 3,73 (suka), sedangkan persentase santan instan memperoleh nilai rata-rata 4,33 (agak suka). Pada uji friedman dapat disimpulkan bahwa tidak ada pengaruh terhadap Macaroni Schotel penggunaan cairan dalam aspek warna, dimana penggunaan cairan susu UHT menghasilkan warna putih kekuningan dan santan segar menghasilkan warna putih yang keduanya disukai panelis. 
TABEL 3. Hasil Uji Validasi Aspek Rasa

\begin{tabular}{|c|c|c|c|c|c|c|c|}
\hline \multirow{3}{*}{ Kategori } & \multirow{3}{*}{ Skor } & \multicolumn{6}{|c|}{ Schotel Penggunaan cairan } \\
\hline & & \multicolumn{2}{|c|}{ Susu UHT } & \multicolumn{2}{|c|}{ Santan Segar } & \multicolumn{2}{|c|}{ Santan Instan } \\
\hline & & $\mathbf{n}$ & $\%$ & n & $\%$ & n & $\%$ \\
\hline Sangat suka & 5 & 10 & 33,3 & 13 & 43,3 & 20 & 66,6 \\
\hline Suka & 4 & 18 & 60 & 14 & 46,6 & 8 & 26,6 \\
\hline Agak suka & 3 & 2 & 6,6 & 3 & 10 & 2 & 6,6 \\
\hline Tidak suka & 2 & 0 & 0 & 0 & 0 & 0 & 0 \\
\hline Sangat tidak suka & 1 & 0 & 0 & 0 & 0 & 0 & 0 \\
\hline Jumlah (n) & & 30 & 100 & 30 & 100 & 30 & 100 \\
\hline Mean & & \multicolumn{2}{|c|}{4,26} & \multicolumn{2}{|c|}{4,33} & \multicolumn{2}{|c|}{4,6} \\
\hline
\end{tabular}

Pada aspek rasa Macaroni Schotel penggunaan cairan menghasilkan nilai rata-rata sebesar 4,26 (suka) pada susu UHT, lalu nilai rata-rata 4,33 (suka) diperoleh dari persentase santan segar, dan nilai rata-rata sebesar 4,6 (agak suka) pada persentase santan instan. Setelah uji friedman didapatkan hasil bahwa tidak terdapat pengaruh pada Macaroni Schotel penggunaan cairan dalam aspek rasa. Penggunaan santan segar lebih disukai konsumen karena memiliki rasa yang gurih daripada santan instan yang memiliki rasa yang cenderung manis menurut Indriastuti, Y. (2014, Juli 01). Penggunaan santan kelapa instan yang terlalu tinggi akan memberikan rasa kurang enak (agak tengik). Menurut Ketaren (1986), hal ini disebabkan santan kelapa mengandung persenyawaan betaionone yang menyebabkan bau dan rasa yang khas pada santan kelapa.

TABEL 4. Hasil Uji Validasi Aspek Tekstur

\begin{tabular}{|c|c|c|c|c|c|c|c|}
\hline \multirow{3}{*}{ Kategori } & \multirow{3}{*}{ Skor } & \multicolumn{6}{|c|}{ Macaroni Schotel Penggunaan cairan } \\
\hline & & \multicolumn{2}{|c|}{ Susu UHT } & \multicolumn{2}{|c|}{ Santan Segar } & \multicolumn{2}{|c|}{ Santan Instan } \\
\hline & & $\mathbf{n}$ & $\%$ & $\mathbf{n}$ & $\%$ & n & $\%$ \\
\hline Sangat suka & 5 & 5 & 16,6 & 8 & 26,6 & 7 & 23,3 \\
\hline Suka & 4 & 25 & 83,3 & 22 & 73,3 & 23 & 76,6 \\
\hline Agak suka & 3 & 0 & 0 & 0 & 0 & 0 & 0 \\
\hline Tidak suka & 2 & 0 & 0 & 0 & 0 & 0 & 0 \\
\hline Sangat tidak suka & 1 & 0 & 0 & 0 & 0 & 0 & 0 \\
\hline Jumlah (n) & & 30 & 100 & 30 & 100 & 30 & 100 \\
\hline Mean & & \multicolumn{2}{|c|}{4,16} & \multicolumn{2}{|c|}{4,26} & \multicolumn{2}{|c|}{4,23} \\
\hline
\end{tabular}

Dalam aspek tekstur pada Macaroni Schotel penggunaan cairan susu UHT menghasilkan nilai rata-rata 4,16 (suka), santan segar menghasilkan nilai rata-rata 4,26(suka) dan santan instan menghasilkan nilai rata-rata 4,23 (suka). Hasil dari uji friedman yang dilakukan adalah tidak terdapat pengaruh pada Macaroni Schotel penggunaan cairan dalam aspek tekstur. Penggunaan susu full cream dapat digunakan untuk meningkatkan rasa dan juga tekstur yang lebih padat pada produknya (Fadaei et al., 2012) sehingga konsumen lebih menyukai macaroni schotel dengan susu UHT.

\section{KESIMPULAN}

Hasil dari uji deskriptif menghasilkan data ranking dari 3 perlakuan dalam 4 aspek, yang pertama pada aspek warna, skor mean tertinggi yaitu 4,33 di dapati oleh perlakuan santan instan, 4,03 pada perlakuan susu UHT, dan 3,73 pada perlakuan santan segar. Pada aspek aroma, skor mean tertinggi yaitu 4,26 di dapati oleh perlakuan santan instan, 4 pada perlakuan santan segar, dan kemudian skor 4 pada perlakuan susu UHT. Pada aspek rasa, skor mean tertinggi yaitu 4,6 di dapati oleh perlakuan santan instan, 4,33 pada perlakuan santan segar, dan 4,26 pada perlakuan susu UHT. Pada aspek tekstur, skor mean tertinggi yaitu 4,26 di dapati oleh perlakuan santan segar, 4,23 pada perlakuan 
santan instan, dan 4,16 pada perlakuan susu UHT. Dari hasil data di atas, maka dapat disimpulkan bahwa santan instan lebih dapat diterima oleh masyarakat dikarenakan memiliki nilai skor lebih tinggi dibandingkan dua perlakuan lainnya pada sektor warna, rasa, dan aroma sehingga formula penggunaan santan instan sudah dapat dikembangkan serta dipasarkan

\section{REFERENSI}

Adhiguna, Aninda, 2018. 'Analisis Tingkat Kesukaan Macaroni Kering pada Mahasiswa Program Studi Pendidikan Fisika 2018 Universitas Negeri Jakarta'. Universitas Negeri Jakarta. Jakarta.

Alsuhendra dan Ridawati. 2008. 'Prinsip Analisis Zat Gizi Dan Penilaian Organoleptik Bahan Makanan'. Jakarta. UNJ Press.

Arbi, Armein Syukri. 2009. 'Pengenalan Evaluasi Sensori'. Universitas Terbuka. Jakarta.

Arikunto. 2006. 'Prosedur Penelitian Suatu Pendekatan Praktek'. PT. Rineka Cipta. Jakarta.

Atmadja Yohanes. 2017. 'Jenis Keju dan Pembuatan Keju'. Akses Online 14 November 2020. URL: https://adoc.pub/jenis-keju-dan-pembuatan-keju.html

Azrai, M., Andayani, N. N., dan Talanca, A. H. (2017). 'Asal Usul dan Taksonomi Tanaman Gandum'. Balai Penelitian Tanaman Serealia.

Brotodjojo, Linda Carolina. 2009. 'All About Pasta - Membuat Dan Mengolah Pasta Sendiri'. PT Gramedia Pustaka Utama. Jakarta.

Buckle, K. A., R. A.Edward,G.H. Fleet dan M.Woods, 1987. 'Ilmu Pangan'. Universitas Indonesia Press. Jakarta (Diterjemahkan oleh H. Purnomo dan Adiono).

De Vita, Oretta Zanini. 2009. 'Encyclopedia Of Pasta'. University Of California Press. Akses Online $22 \quad$ November 2019, URL : https://books.google.co.id/books?id=D5nXAbSifIgC\&pg=PA89\&hl=id\&source=gbs_selected_pa ges $\&$ cad $=3 \# v=$ onepage $\& \mathrm{q} \& \mathrm{f}=$ false

Dharmayanti Laksmi. 2013. 'Pengetahuan Bahan Makanan 2'. Kementrian Pendidikan dan Kebudayaan. Jakarta.

Fikriyananda, Muhamad. 2016. 'Studi Pembuatan Macaroni Schotel Dengan Penambahan Buah Pepaya Mentah dan Matang Sebagai Sumber Pangan Lokal'. Universitas Pendidikan Indonesia. Sumedang

Hayati, Rita. 2010. 'Profil Asam Lemak Dan Triasilgliserol Berantai Sedang (MCFA) Dalam Kelapa Segar Dan Santan (Cocos nucifera L)'. Universitas Syiah Kuala. Aceh.

Indriastuti, Y. 2014. 'Antara santan segar dan instan'. Republika. Diambil dari https://www.republika.co.id. Diakses pada tanggal 7 Maret 2021.

Irmansyah,J. dan Kusnadi. 2009. 'Sifat Listrik Telur Ayam Kampung Selama Penyimpanan'. Media Peternakan.

Ketaren, S. 2005. 'Minyak dan Lemak Pangan'. Jakarta: UI-Press.

Koeswara, Sutrisno. 2007. 'Produk Pasta, Beraneka Bentuk Dan Rupa'. Rajawali Press. Jakarta.

Kumolontang, Nova. 2015. 'Pengaruh Penggunaan Santan Kelapa Dan Lama Penyimpanan Terhadap Kualitas "Cookies Santang". Baristand Industri Manado. Manado.

Lazuardi, Alam. 2008. 'Analisis Strategi Pengembangan Usaha Restoran Macaroni Panggang (MP) Bogor'. Institut Pertanian Bogor. Bogor.

Mandasari, Rizky. 2018. 'Cara Membuat Macaroni Schotel Sederhana, Lezat, Dan Lumer Di Mulut'. Liputan6.com. Akses Online 22 Desember 2019, URL 
https://www.liputan6.com/lifestyle/read/3693967/cara-membuat-macaroni-schotel-sederhanalezat-dan-lumer-di-mulut

Mc Guire, Sania. 2012. 'Pasta'. Akses Online 22 November 2019, URL : https://www.scribd.com/doc/101411485/Pasta

Nita, Theresia. 2011. 'Kornet'. http://id.scribd.com/doc/71785227/Kornet. Diakses 21 November 2020.

Nisa, Chairun, Trioso Purnawarman, Ita Djuwita, dan Chusnul Choliq. 2009. 'Produksi dan Uji Biologis Rennet dari Abomasum Domba Lokal sebagai Bahan Bioaktif dalam Pembuatan Keju'. Fakultas Kedokteran Hewan, Institut Pertanian Bogor. Bogor

Panglipur, Praviantie Estine. 2014. 'Pengaruh Jumlah Salad Oil dan CMC (Carboxy Methyl Cellulose) Terhadap Sifat Organoleptik Kornet Daging Sapi’. Universitas Negeri Surabaya. Surabaya.

Rakhmah Risza Fawzia. 2013. 'Pemanfaatan Buah Lokal sebagai Koagulan dalam Pembuatan Soy Cheese'. Fakultas Keguruan dan Ilmu Pendidikan, UMS, Surakarta

Santoso, Gloria Jessica. 2016. 'Uji Formula Yoghurt Susu UHT (Ultra High Temperature) Dengan Penambahan Daun Katuk (Sauropus Andogynus) Secara Organoleptik'. Universitas Sanata Dharma. Yogyakarta.

Sediaoetama, A.D. 1985. 'Ilmu Gizi'. Jilid I. Penerbit Dian Rakyat. Jakarta.

Sidik,Suci L., Fatimah Feti., \& Sangi, Meike S. 2013. 'Pengaruh Penambahan Emulsifier Dan Stabilizer Terhadap Kualitas Santan Kelapa'. Universitas Sam Ratulangi. Manado.

Soeparno. 2005. 'Ilmu dan Teknologi Daging'. Yogyakarta. Gadjah Mada University Press.

Soro, Megmerio., Bahri, Syaiful., Rahim, Erwin Abdul. 2016 'Pemanfaatan Santan Instan Kadaluarsa Untuk Produksi Minyak Secara Fermentasi'. Universitas Tadulako.

Sugiyono. 2010. 'Metode Penelitian Pendidikan'. Alfabeta. Bandung.

Tansakul, A., Chaisawang, P. 2006. 'Thermophsical Properties Of Coconut Milk'. J.Food Enginering.

Tabularasa. 2018. 'Pasta'. Esensi Erlangga Group. Jakarta

Wikaningtyas Annisa Khaira. 2010. 'Susu (susu segar, full cream, yoghurt, yakult, dan SKM)'. Fakultas Teknik, Universitas Pasundan. Bandung

Winarno, F. G. 1993. 'Pangan Gizi', Teknologi dan Konsumen. Gramedia Pustaka Utama. Jakarta.

Yulneriwarni, Sulastri, dan Lydia Tuti. 2009. 'Fermentasi Keju dari Berbagai Jenis Kacang Menggunakan Isolat Bakteri Asam Laktat dan Nenas'. Fakultas Biologi,Universitas Nasional. Jakarta 